\title{
Impacts of boundary layer turbulence and land surface process parameterizations on simulated sea breeze characteristics
}

\author{
J.-F. Miao' ${ }^{1}$, K. Wyser ${ }^{2}$, D. Chen ${ }^{3}$, and H. Ritchie ${ }^{4,5}$ \\ ${ }^{1}$ Key Laboratory of Meteorological Disaster of Ministry of Education, and College of Atmospheric Sciences, Nanjing \\ University of Information Science and Technology, 219 Ningliu Road, Nanjing 210044, China \\ ${ }^{2}$ Rossby Centre, Swedish Meteorological and Hydrological Institute (SMHI), 60176 Norrköping, Sweden \\ ${ }^{3}$ Department of Earth Sciences, University of Gothenburg, P.O. Box 460, 40530 Gothenburg, Sweden \\ ${ }^{4}$ Department of Oceanography, Dalhousie University, 1355 Oxford Street, Halifax, NS, B3H 4J1, Canada \\ ${ }^{5}$ Meteorological Research Division, Environment Canada, 45 Alderney Drive, Dartmouth, NS B2Y 2N6, Canada
}

Received: 21 October 2008 - Revised: 6 May 2009 - Accepted: 25 May 2009 - Published: 8 June 2009

\begin{abstract}
This paper investigates the sensitivity of sea breeze (SB) simulations to combinations of boundary-layer turbulence and land-surface process parameterizations implemented in the MM5 mesoscale meteorological mode for an observed SB case over the Swedish west coast. Various combinations from four different planetary boundary layer (PBL) schemes [Blackadar, Gayno-Seaman (GS), Eta, $\mathrm{MRF}$, and two land surface model (LSM) schemes (SLAB, Noah) with different complexity are designed to simulate a typical SB case over the Swedish west coast. The simulations are conducted using two-way interactively nested grids. Simulated 10-m winds are compared against observed nearsurface wind data from the GÖTE2001 campaign to examine the diurnal cycle of wind direction and speed for SB timing. The SB (vertical) circulation is also compared in the different experiments. The results show that the different combinations of PBL and LSM parameterization schemes result in different SB timing and vertical circulation characteristics. All experiments predict a delayed SB. The vertical component of the SB circulation varies in the experiments, among which the GS PBL scheme produces the strongest SB circulation. Evident differences between the SLAB and Noah LSMs are also found, especially in maximum of updraft and downdraft velocities of the SB vertical circulation. The results have significant implications for convective initiation, air quality studies and other environmental problems in coastal areas.
\end{abstract}

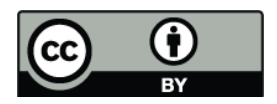

Correspondence to: J.-F. Miao (miaoj@nuist.edu.cn)
Keywords. Atmospheric composition and structure (Biosphere-atmosphere interactions; Evolution of the atmosphere) - Meteorology and atmospheric dynamics (Mesoscale meteorology; Turbulence)

\section{Introduction}

Sea breeze (SB) is an important mesoscale meteorological phenomenon in coastal areas caused by a thermal difference between sea and land during the daytime. It is a main feature of surface heterogeneities which force mesoscale atmospheric circulations, and has been studied observationally, experimentally, theoretically and numerically for a long time (Abbs and Physick, 1992; Simpson, 1994; Miller et al., 2003).

Also, SB is the prototypical mesoscale circulation and was the first to be simulated in numerical models (Angevine et al., 2006). Its theoretical background is well understood and simple enough, but real SB is very sensitive to real environmental complexity, surface temperature, and large scale background flow (Zhong and Takle, 1993; Angevine et al., 2006). SB circulation plays an important role in air pollution transport and dispersion (Ding et al., 2004; Oh et al., 2006). It affects human activities not only along the coast but also further inland. Therefore, SB study is still an interesting and challenging subject (Miao et al., 2003; Angevine et al., 2006; Drobinski et al., 2006; Prtenjak and Grisogono, 2007; Srinivas et al., 2007).

Air quality is very sensitive to the details of local circulations (Seaman, 2000; Augustin et al., 2006). Since

Published by Copernicus Publications on behalf of the European Geosciences Union. 
meteorological fields (weather data) are used as input to air quality models, small errors in meteorological simulations, which may be of minor concern for weather forecasting, may nevertheless lead to erroneous air quality predictions (Zhong et al., 2007). Previous studies have suggested the importance of understanding SB timing in pollutant transport and accumulation in coastal areas (e.g., Ding et al., 2004; Oh et al., 2006). The results have shown that late onset of SB-induced stagnant conditions in the morning allows pollutant concentration to build up and enhances ozone accumulation in the afternoon. The delayed SB can contribute to the daytime transport of pollution and high ozone on the coast (Ding et al., 2004).

Over the past years, the SB has been extensively studied over the Swedish west coast with a focus on observational analyses (Gustavsson et al., 1995; Borne et al., 1998) to improve our understanding of this meteorological phenomenon. Nevertheless, to our knowledge, very few modelling efforts over this area can be found in the literature. With the development of the study of air pollution dynamics, SB simulations at high resolutions over this area, where the second largest city (Gothenburg) in Sweden is located, are needed to understand SB dynamics at fine scales and its implications for air pollution transport and dispersion.

The turbulence parameterization, or PBL parameterization, is one of most important model components in the meteorological and air quality models (Pleim, 2007). It accounts for the vertical mixing of atmospheric fields induced by small-scale turbulent motions, which are usually not resolved on the model grid (Zängl et al., 2008), and is very important for accurate simulations of boundary-layer temperature, humidity, wind, and mixed-layer depth (Berg and Zhong, 2005).

The land surface model (LSM), in which land-surface processes are parameterized, provides surface sensible and latent heat fluxes as lower boundary conditions to coupled atmospheric model. These heat and moisture fluxes are then transported throughout the planetary boundary layer (PBL) and interact with other model physics including cloud, radiation and precipitation processes (Chen and Dudhia, 2001b). In other words, surface heat, moisture, momentum fluxes, and short and long wave radiations are the primary factors driving the development of the turbulent boundary layer (Seaman, 2000). Also, the advection of cold and moist air by SB can lead to important modifications to the land surface fluxes, and thus have consequences on the boundary layer development.

The previous studies have shown that the simulation of SB circulation caused by land-sea air temperature contrast is closely linked to boundary-layer turbulence and land-surface processes simulations. For example, Prtenjak and Grisogono (2002) investigated the influence of land surface roughness length on the strength of SB circulation, and found that very rough surfaces weaken the SB circulation during the day, causing a slower inland penetration. In turn, the enhanced turbulent fluxes cause onset of the SB circulation earlier
(Malda et al., 2007). Miao et al. (2003) examined the impact of land degradation (desertification) on the SB circulation characteristics by using the Regional Atmospheric Modelling System (RAMS) model, suggesting that land degradation (land cover change and soil moisture decrease) results in an enhanced SB circulation and significantly influences the SB pattern and magnitude.

The MM5 mesoscale meteorological model (Grell et al., 1995) is a limited-area, non-hydrostatic, terrain-following sigma-coordinate primitive equation model designed to simulate or predict mesoscale atmospheric circulations, and it has been widely applied in operational numerical weather forecasting (Zhong et al., 2005; Akylas et al., 2007) and air quality studies (e.g., Ding et al., 2004; Miao, 2006; Miao et al., 2006, 2008; Mao et al., 2006; Bossioli et al., 2009). It is also increasingly used in SB modelling (e.g., Colby, 2004; Zhu and Atkinson, 2004; Oh et al., 2006; Srinivas et al., 2007; Dandou et al., 2009a). This model provides modelers with many options of physical parameterization schemes for cumulus convection, microphysics, radiation, PBL turbulence, and land surface processes. Among the various parameterizations representing different physical processes, PBL and LSM parameterizations are especially important for simulations of atmospheric properties and local circulations (Zhong et al., 2007), and thus have critical implications for air quality simulations (Pérez et al., 2006; Pleim, 2007).

Several PBL and LSM parameterization schemes have been developed and implemented into MM5, representing different turbulence closure assumptions and various degrees of complexity. Over the last two decades, various PBL parameterization schemes have been extensively evaluated and intercompared over several geographical areas at different spatial and temporal scales for different weather events or meteorological variables, but most of these studies were limited to comparisons of PBL schemes coupled with a simple slab LSM (e.g., Braun and Tao, 2000; Bright and Mullen, 2002; Wisse and Vilà-Guerau de Arellano, 2004; Zhang and Zheng, 2004; Berg and Zhong, 2005; Bianco et al., 2006; Pérez et al., 2006; Akylas et al., 2007; Srinivas et al., 2007; Tombrou et al., 2007; Thomsen and Smith, 2008; Zängl et al., 2008; Bossioli et al., 2009; Dandou et al., 2009b). Only a few studies evaluated and compared PBL parameterization schemes coupled with an advanced LSM (e.g., Mao et al., 2006; Miao et al., 2007, 2008; Zhong et al., 2007; Han et al., 2008). These studies indicate that the simulated results are sensitive to PBL and LSM parameterizations, with the sensitivity being dependent on simulated variables or events, weather conditions, geographical areas, as well as spatial and temporal scales. For example, Zhang and Zheng (2004) examined the sensitivity of simulations of the diurnal cycle of surface wind and temperature to five different PBL schemes in MM5 for a convectively mixed weather situation over flat terrain, and found that the simulated near-surface temperature and wind speed to a larger extent depend on the choice of PBL schemes. Although some of the schemes compared 
Table 1. Summary of numerical experiments.

\begin{tabular}{lcccccccc}
\hline \multirow{2}{*}{ Experiment $^{\mathrm{a}}$} & \multicolumn{3}{c}{ PBL parameterization $^{\mathrm{b}}$} & & \multicolumn{2}{c}{ LSM parameterization } \\
\cline { 2 - 3 } & Blackadar & GS & Eta & MRF & & SLAB & Noah \\
\hline BLKSLAB (BS) & $\times$ & & & & & $\times$ & \\
GSSLAB (GS) & & $\times$ & & & & $\times$ & \\
EtaSLAB (ES) & & & $\times$ & & & $\times$ & \\
MRFSLAB (MS) & & & & $\times$ & & $\times$ & \\
EtaNOAH (EN) & & & $\times$ & & & & $\times$ \\
MRFNOAH (MN) & & & & $\times$ & & & $\times$ \\
\hline
\end{tabular}

a Abbreviations of the experiments are given in the parentheses.

$\mathrm{b}$ Moist vertical diffusion is used in Blackadar and MRF PBLs; Thermal roughness length uses Zilitinkevich formulation in Blackadar and MRF PBLs.

well with observations of temperature, all simulations had significant errors in wind speed. The similar results are also found in Miao et al. (2008).

Of the above cited studies, only a few examined the impacts of PBL and/or LSM parameterization schemes on simulated SB (e.g., Srinivas et al., 2007; Zhong et al., 2007) and diurnal cycle of near-surface wind (e.g., Zhang and Zheng, 2004; Miao et al., 2008) despite the fact that SB is a prototypical mesoscale circulation and that diurnal cycle of winds has significant implications for air quality studies.

The above-mentioned limitations and motivations lead to this study. The purpose is to simulate the SB at high resolutions using the MM5 model and to study the sensitivity of simulated SB characteristics, in particular timing and strength, to different combinations of PBL and LSM parameterization schemes in the model. The results are then compared against the measurement data from the GÖTE2001 field campaign (Borne et al., 2005).

As an extension and supplement to Miao et al. (2008), this study focuses on the applications of MM5 mesoscale model to SB simulation, and includes one PBL scheme which was not examined there.

\section{Model setup and numerical experiments}

The model is set up with four two-way nested domains (D1, D2, D3, and D4) with horizontal grid spacing of 54, 18, 6, 2-km, respectively (Fig. 1a). D1 is used to simulate the large scale meteorological conditions. The inner three domains with increasingly finer resolution are used to capture mesoscale and local scale features. The innermost domain (D4) is the area of interest (Fig. 1b). There is a remarkable sea-land contrast in D4, and the coastline is in an approximately north-south direction. All domains have 35 vertical full sigma levels and the model top is at $100 \mathrm{hPa}$. To allow the model to resolve SB circulations at higher resolutions, about 18 levels (half- $\sigma$ level) are set up within the lowest
$2 \mathrm{~km}$. The height of the lowest model level (half- $\sigma$ layer) is about $10 \mathrm{~m}$, representing the average over the lowest $20 \mathrm{~m}$ above the surface.

In this study, the four widely-used PBL parameterization schemes [Blackadar PBL scheme (Blackadar, 1976, 1979; Zhang and Anthes, 1982), Gayno-Seaman (GS) PBL scheme (Shafran et al., 2000), Eta PBL scheme (Janjić, 1990, 1994), and MRF PBL scheme (Hong and Pan, 1996)] and two LSM parameterization schemes [SLAB LSM (Dudhia, 1996) and Noah LSM (Chen and Dudhia, 2001a)] in MM5, Version 3.6.3, are chosen based on: (1) availability of coupling of PBL schemes and LSMs, and (2) that LSM can be coupled with more than one PBL scheme, in the model. Table 1 presents the different combinations of PBL and LSM parameterizations used in the experiments.

Of the above four PBL schemes chosen, the Blackadar and MRF PBLs are based on a first-order closure and apply nonlocal vertical mixing in the free convective regime, but the method of calculating the vertical mixing profiles differs substantially between the schemes. The Eta and GS PBLs apply a TKE closure with local vertical mixing in all stability regimes. The formulae used to calculate the mixing coefficients are quite similar in the Eta and GS PBL schemes, but the Eta scheme uses the ordinary potential temperature as conserved variables whereas the GS scheme uses the liquidwater potential temperature. In all cases, the mixing applied by the PBL schemes acts solely in the vertical direction in MM5, while the horizontal diffusion is dominated by the computational mixing required for numerical stability (Zängl et al., 2008). In addition, the Blackadar and MRF PBL schemes are also referred to as "first-order schemes", while the GS and Eta PBL schemes referred to as "TKEbased schemes". For the further details or summary descriptions of the above PBL schemes, the reader may also refer to Zhang and Zheng (2004), Wisse and Vilà-Guerau de Arellano (2004), Berg and Zhong (2005), Bianco et al. (2006), Tombrou et al. (2007), Miao et al. (2008), and Thomsen and Smith (2008). 


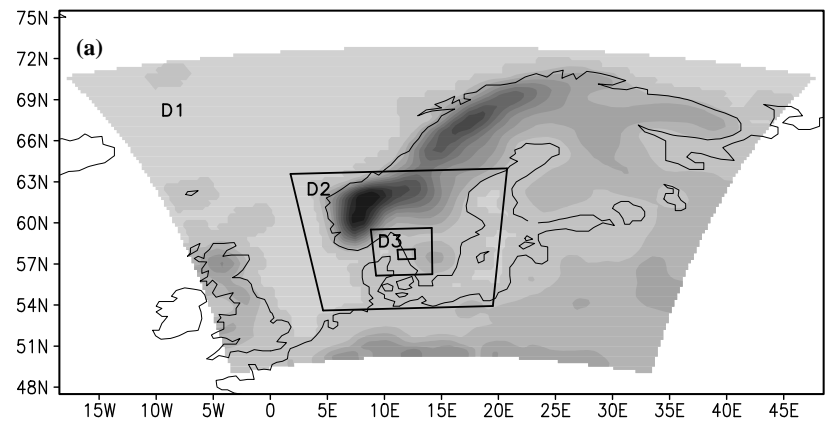

$0 \quad 100200300 \quad 400 \quad 500 \quad 600 \quad 700 \quad 80090010001100$

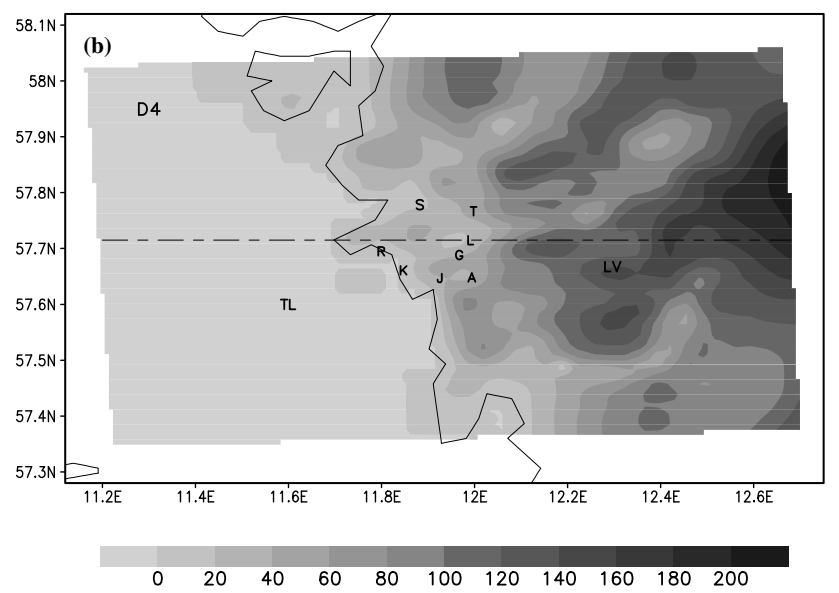

Fig. 1. (a) Modelling domains and grid configuration. Domains 1 , 2, 3, and 4 (denoted by D1, D2, D3 and D4) have a horizontal grid resolution of $54,18,6$ and $2 \mathrm{~km}$, respectively. Four domains consist of $50 \times 50,64 \times 55,62 \times 52$, and $40 \times 46$ horizontal gridcells (N-S direction by E-W direction), respectively. Innermost domain refers to D4. Shaded is model terrain (in meters) with $54-\mathrm{km}$ grid resolution for D1; (b) Zooming-in model area of interest (D4) and model terrain (shaded in meters) with 2-km grid resolution, as well as locations of observational sites by letters: $\mathrm{K}$ (Kanotföreningen), R (Risholmen), J (Järnbrott), A (Åby), G (GVC), L (Lejonet), T (Tagene), S (Säve), TL (Trubaduren), and LV (Landvetter). Dashed line indicates location of the vertical cross-section used in this study (along $57.72^{\circ} \mathrm{N}$ ).

Also, of the two LSM schemes chosen, the SLAB LSM is a simple LSM while the Noah LSM is an advanced LSM. In this study, the SLAB LSM consists of: (1) a five-layer soil temperature model (Dudhia, 1996), and (2) a bucket soil moisture model (Manabe, 1969). The model is used to predict the soil temperature in the five layers with thickness from top to bottom of $1,2,4,8$ and $16 \mathrm{~cm}$, and keeps a budget of soil moisture allowing moisture availability to vary with time in response to rainfall and evaporation rates. The Noah LSM is used to predict soil moisture and temperature in four layers with thickness from top to bottom of 10, 30, 60 and $100 \mathrm{~cm}$, as well as canopy moisture and water-equivalent snow depth.
It uses soil and vegetation types in handling evapotranspiration. The dominant vegetation type in each grid is selected to represent the grid vegetation characteristics when the model horizontal grid resolution is larger than $1 \mathrm{~km} \times 1 \mathrm{~km}$.

The other physics options used in this study are: AnthesKuo convection scheme in D1 and Kain-Fritsch convection including shallow convection (KF2; Kain, 2004) in D2-D4. It is necessary to mention that convection parameterization is also applied in D4 with less than $5 \mathrm{~km}$ grid spacing as the KF2 scheme has been updated recently and also includes shallow convection for a potential improvement at higher resolutions (also refer to Bélair and Mailhot, 2001). The Dudhia simple ice microphysics scheme (Dudhia, 1989), Rapid Radiative Transfer Model (RRTM) longwave scheme (Mlawer et al., 1997) and Dudhia cloud-radiation shortwave scheme (Dudhia, 1989) are used for all domains.

The initial and boundary conditions were taken from the European Center for Medium-Range Weather Forecasts (ECMWF) operational analysis archive data with a spatial resolution of $0.5^{\circ}$ by $0.5^{\circ}$ and a temporal resolution of six hours. The USGS 25-category land use data and terrain data, as well as global 17-category soil type data are used. The topography for the coarse domain (D1) with $54 \mathrm{~km} \times 54 \mathrm{~km}$ resolution is shown in Fig. 1a, while that for the innermost domain (D4) with $2 \mathrm{~km} \times 2 \mathrm{~km}$ is shown in Fig. 1b. As seen from Fig. 1b, the terrain height in D4 varies from a few meters near the coastal lines to about $200 \mathrm{~m}$ over the inland areas. Moreover, soil moisture is initialized for the LSMs using the ECMWF data.

The 48-h simulations for all numerical experiments are performed, starting from 00:00 UTC 7 May 2001 with model output at one-hour intervals. The first $24 \mathrm{~h}$ are discarded as model spin-up, while the last 24-h simulation results are analyzed as the second day of the simulations (8 May 2001) has been identified as a typical SB case from the observations during the GÖTE2001 field campaign (Borne et al., 2005).

\section{GÖTE2001 data and analysis methods}

The GÖTE2001 field campaign (Borne et al., 2005) was conducted in the greater Gothenburg area along the Swedish west coast in a 2-week period from 7 to 20 May 2001. Based on the campaign data, one typical SB day (8 May 2001) is chosen in this study by following the criteria of Borne et al. (1998) for identifying SB days. The dataset used in this study is summarized in Table 2. In Borne et al. (1998), six different filters were used to identify an SB day, of which the primary criterion is the occurrence of a distinct change in surface wind direction within a $24-\mathrm{h}$ period. In this study, the 2-m air temperature at Säve (S) and Trubaduren (TL) from the campaign, as shown in Fig. 1b, is used to characterize the temperature difference between sea and land as one filter, and wind speed and direction at 700-hPa level from the radiosounding observation (RAOB) at Landvetter 
Table 2. Name, location and other information for observational sites used in this study (Lat: latitude, Lon: longitude, Elev: elevation), as well as model terrain (TER) height and dominant land use (LU) represented in 2-km resolution (D4) closest to observational sites.

\begin{tabular}{lccccccc}
\hline Site name $^{\mathrm{a}}$ & Lat $\left.^{\circ} \mathrm{N}\right)$ & Lon $\left({ }^{\circ} \mathrm{E}\right)$ & Elev $^{\mathrm{b}}(\mathrm{m})$ & Measured variable $^{\mathrm{d}}$ & Source $^{\mathrm{e}}$ & $\mathrm{TER}^{\mathrm{b}}(\mathrm{m})$ & LU \\
\hline Kanotföreningen & 57.6609 & 11.8476 & $9^{\mathrm{c}}$ & $\mathrm{WS}_{2}, \mathrm{WD}_{2}$ & RCG & 0 & Water \\
Risholmen & 57.6950 & 11.7995 & 10 & $\mathrm{WS}_{35}, \mathrm{WD}_{35}$ & Miljo- & 0 & Water \\
Järnbrott & 57.6472 & 11.9259 & 7 & $\mathrm{WS}_{16}, \mathrm{WD}_{16}$ & Miljo- & 40 & Urban \\
Åby & 57.6483 & 11.9941 & 8 & $\mathrm{WS}_{10}, \mathrm{WD}_{10}$ & Miljo- & 43 & Urban \\
GVC & 57.6886 & 11.9663 & $85^{c}$ & $\mathrm{WS}_{7}, \mathrm{WD}_{7}$ & RCG & 43 & Urban \\
Lejonet & 57.7149 & 11.9917 & 3 & $\mathrm{WS}_{10}, \mathrm{WD}_{10}$, & Miljo- & 24 & Urban \\
Tagene & 57.7670 & 11.9979 & 3 & $\mathrm{WS}_{10}, \mathrm{WD}_{10}$ & Miljo- & 45 & Crop \\
Säve & 57.7786 & 11.8824 & 16 & $\mathrm{~T}_{2}$ & SMHI & 18 & Forest \\
Trubaduren & 57.5960 & 11.6352 & - & $\mathrm{T}_{2}$ & SMHI & 0 & Water \\
Landvetter & 57.6678 & 12.2963 & 169 & RAOB $_{2}$ & NOAA & 136 & Forest \\
\hline
\end{tabular}

${ }^{a}$ Refer to Fig. $1 b$ for the locations in D4. Järnbrott is a mast site, and the first level for wind measurement is at $16 \mathrm{~m}$ high. Säve is a routine weather station, and Landvetter is a radiosounding station; Trubaduren is a lighthouse station.

b Unit: meters ASL (Above Sea Level)

${ }^{\mathrm{c}}$ Height of mounted measurement mast from the sea level to the roof. For Kanotföreningen, the elevation is $3 \mathrm{~m}$, and the building height is $6 \mathrm{~m}$; For GVC, the elevation is $60 \mathrm{~m}$, and the building height is $25 \mathrm{~m}$.

$\mathrm{d}$ WS: wind speed; WD: wind direction. Subscript represents the measured height above ground level (a.g.l.) or above the roof; RAOB: radiosounding; Hourly data for all sites except for Säve, Trubaduren and Landvetter (3-h time interval $T_{2}$ at Säve and Trubaduren, and 12-h time interval RAOB at Landvetter).

e Miljo-: Environment Administration, City of Gothenburg; RCG: Regional Climate Group; SMHI: Swedish Meteorological and Hydrological Institute.

is used to represent synoptic-scale background flow. On 8 May 2001, the Swedish west coast was dominated by a high pressure system. The synoptic-scale background wind is southeasterly $\left(5.7 \mathrm{~m} \mathrm{~s}^{-1}\right)$, easterly $\left(6.2 \mathrm{~m} \mathrm{~s}^{-1}\right)$, and southerly $\left(7.2 \mathrm{~m} \mathrm{~s}^{-1}\right)$ at 00:00 UTC, 12:00 UTC, and 24:00 UTC, respectively (Miao, 2006). The flow is an offshore synoptic wind during the daytime, and thus favors SB development (Zhong and Takle, 1993; Miao et al., 2003). Also, the observed cloud cover data at the Säve site shows that 8 May 2001 is a clear sky day (Miao et al., 2008), and hence the SB event chosen is a clear-sky SB case.

\section{Sea breeze timing and strength}

In this study, the observed near-surface wind data from the campaign is used to compare with the simulated near-surface wind ( $10 \mathrm{~m}$ a.g.l.) at the closest grid point from D4 with 2-km grid spacing. The simulated $10-\mathrm{m}$ wind is not adjusted vertically to the measurement heights, although there are some differences between the model levels and the measurement heights (Miao et al., 2008). It is noted that surface measurement represents a value only at a given horizontal location and height, while the simulated result represents a volumeaveraged value.

To examine the impacts of different combinations of PBL and LSM parameterization schemes on simulated SB in timing, "SB timing" is characterized at certain sites in this study by three feature parameters (cf. Prezerakos, 1986): SB on- set $\left(\tau_{s}\right), \mathrm{SB}$ end time ("cessation") $\left(\tau_{e}\right)$, and the time ( $\left.\tau_{\max }\right)$ when the near-surface wind speed reaches a first peak value during the daytime. The value of wind speed at time $\tau_{\max }$ is defined as "SB strength" in this study.

The $\tau_{s}$ is defined according to the following criteria that must all be fulfilled: 1) there is sharp change in wind direction (greater than $30^{\circ}$ ) around time $\tau_{s} ; 2$ ) the wind direction at time $\tau_{s}$ is in the range of $180^{\circ}$ to $360^{\circ} ; 3$ ) the wind speed at time $\tau_{s}+1$ is greater than that at time $\tau_{s}$. These three criteria must be met concurrently. The $\tau_{e}$ is reached if any of the following criteria is met: 1) the wind direction at time $\tau_{e}$ is in the range of $180^{\circ}$ to $360^{\circ}$, but that at time $\tau_{e}+1$ is beyond the range of $180^{\circ}$ to $360^{\circ}$; The wind speed at time $\tau_{e}$ is less than that at time $\tau_{e}-1$ or $\left.\tau_{e}+1 ; 2\right)$ the wind direction at time $\tau_{e}-1$ is in the range of $180^{\circ}$ to $360^{\circ}$; The wind speed at time $\tau_{e}$ is less than that at time $\tau_{e}-1$, and less than or equal to $0.5 \mathrm{~m} \mathrm{~s}^{-1}$. Also, during the daytime the wind has to be onshore for at least 2 consecutive hours for recognizing and defining SB onset and cessation (cf. Furberg et al., 2002; Prtenjak and Grisogono, 2007).

Figures 2-8 show the time-series of observed hourly wind direction and wind speed at all the seven observational sites with hourly measurement data [hereafter referred to as the "all (observational) sites"] (cf. Table 2), and simulated hourly wind direction and wind speed from the experiments (Table 1). Table 3 summarizes the SB timing parameters derived from the diurnal variation of wind direction and wind speed (Figs. 2-8), and Table 4 presents the SB strength. For 
Table 3. Observed (OBS) and simulated sea breeze timing (o'clock) with different experiments at all observational sites on 8 May 2001.

\begin{tabular}{|c|c|c|c|c|c|c|c|c|}
\hline \multirow{2}{*}{ Site $^{\mathrm{a}}$} & \multirow{2}{*}{ Timing $^{b}$} & \multirow{2}{*}{ OBS } & \multicolumn{6}{|c|}{ Experiment $^{\mathrm{c}}$} \\
\hline & & & BS & GS & ES & MS & $\mathrm{EN}$ & $\mathrm{MN}$ \\
\hline \multirow[t]{3}{*}{ Kanotföreningen } & Start time & 8 & 9 & 11 & 12 & 9 & 12 & 9 \\
\hline & End time & 21 & 20 & 21 & 21 & 22 & 20 & 20 \\
\hline & Time of max SB & 15 & 16 & 15 & 15 & 15 & 15 & 15 \\
\hline \multirow[t]{3}{*}{ Risholmen } & Start time & 8 & 10 & 11 & 12 & 9 & 12 & 9 \\
\hline & End time & 20 & 21 & 21 & 21 & 22 & 20 & 19 \\
\hline & Time of max SB & 14 & 15 & 15 & 15 & 16 & 15 & 15 \\
\hline \multirow[t]{3}{*}{ Järnbrott } & Start time & 11 & 14 & 13 & 15 & 15 & 18 & 15 \\
\hline & End time & 20 & 20 & 21 & 20 & 21 & 20 & 20 \\
\hline & Time of max SB & 13 & 19 & 15 & 17 & 20 & 19 & 19 \\
\hline \multirow[t]{3}{*}{ Åby } & Start time & 12 & 18 & 15 & 18 & 17 & - & 17 \\
\hline & End time & 21 & 20 & 21 & 20 & 21 & - & 20 \\
\hline & Time of max SB & 14 & 19 & 16 & 18 & 18 & - & 19 \\
\hline \multirow[t]{3}{*}{ GVC } & Start time & 11 & 18 & 14 & 16 & 17 & - & 17 \\
\hline & End time & 20 & 20 & 21 & 20 & 21 & - & 19 \\
\hline & Time of max SB & 14 & 19 & 15 & 18 & 18 & - & 18 \\
\hline \multirow[t]{3}{*}{ Lejonet } & Start time & 14 & - & 15 & 18 & 18 & - & - \\
\hline & End time & 20 & - & 21 & 20 & 21 & - & - \\
\hline & Time of max SB & 14 & - & 16 & 19 & 18 & - & - \\
\hline \multirow[t]{3}{*}{ Tagene } & Start time & 14 & - & 16 & 18 & 18 & - & - \\
\hline & End time & 19 & - & 20 & 21 & 21 & - & - \\
\hline & Time of max SB & 15 & - & 17 & 19 & 19 & - & - \\
\hline
\end{tabular}

\footnotetext{
a The observational sites from top to bottom are sorted by the relative distance to the coastline from near to far. All sites are within the distance of less than $16 \mathrm{~km}$ to coastline.

${ }^{b}$ See the text for definitions; Time of max SB: Occurrence time of Maximum SB; Unit: O'clock (UTC).

${ }^{\mathrm{c}}$ Refer to Table 1 for abbreviations of the experiments.
}

Table 4. Observed (OBS) and simulated sea breeze strengthwith different experiments at all observational sites on 8 May 2001. Sea breeze strength is defined as the first peak value of observed and simulated near-surface wind speed during SB hours (cf. Table 3).

\begin{tabular}{lccccccc}
\hline \multirow{2}{*}{ Site $^{\mathrm{a}}$} & OBS & \multicolumn{6}{c}{ Experiment $^{\mathrm{b}}$} \\
\cline { 3 - 8 } & & BS & GS & ES & MS & EN & MN \\
\hline Kanotföreningen & 5.1 & 6.0 & 5.4 & 6.1 & 3.8 & 6.4 & 4.1 \\
Risholmen & 8.2 & 4.9 & 4.9 & 5.7 & 3.7 & 4.9 & 3.3 \\
Järnbrott & 4.2 & 3.4 & 2.9 & 2.6 & 2.3 & 1.7 & 2.5 \\
Åby & 4.1 & 3.0 & 3.0 & 2.0 & 2.2 & - & 2.7 \\
GVC & 4.5 & 2.3 & 2.9 & 2.3 & 2.2 & - & 2.1 \\
Lejonet & 3.7 & - & 3.3 & 1.9 & 2.5 & - & - \\
Tagene & 4.8 & - & 3.6 & 2.0 & 2.4 & - & - \\
\hline
\end{tabular}

${ }^{\text {a }}$ Refer to the note ${ }^{a}$ of Table 3 .

b Refer to Table 1 for abbreviations of the experiments.

convenience of discussion, the seven observational sites are classified into coastal sites (Kanotföreningen, Risholmen) and inland sites (Järnbrott, Åby, GVC, Lejonet, Tagene). This classification is mainly based on the distance of the sites to the coastline and the dominant land use at the model gridcells (cf. Fig. 1b and Table 2).
As seen from Figs. 2, 3, at the coastal sites all experiments capture the observed SB, but the predicted SB onset shows large differences (Table 3). Compared to the observed SB onset, the predicted SB onset lags 1 to $4 \mathrm{~h}$ at Kanotföreningen and Risholmen sites. Among all experiments, MRFSLAB and MRFNOAH show the best performance in reproducing the observed SB onset, while EtaSLAB and EtaNOAH are the poorest. The BLKSLAB shows the same performance as MRFSLAB and MRFNOAH at Kanotföreningen, but a little poorer than MRFSLAB and MRFNOAH at Risholmen. The difference in the predicted SB end time among various experiments is not significant, and there is only -1 to $2 \mathrm{~h}$ lag from the observed SB end time at Kanotföreningen, and $1 \mathrm{~h}$ lag at Risholmen. Consequently, the simulated SB life span with different experiments displays large differences. It ranges from 8 to $13 \mathrm{~h}$ at Kanotföreningen (observed: $13 \mathrm{~h}$ ), and from 8 to $11 \mathrm{~h}$ at Risholmen (observed: $12 \mathrm{~h}$ ). Further, the simulated SB strength is highly variable among the experiments (Table 4). It varies from 3.8 to $6.4 \mathrm{~m} \mathrm{~s}^{-1}$ at Kanotföreningen, and 3.3 to $5.7 \mathrm{~m} \mathrm{~s}^{-1}$ at Risholmen. The deviation from the observations amounts to -25 to $25 \%$ of observed SB strength at Kanotföreningen, and -59 to $-30 \%$ at Risholmen.

It is interesting to notice that at Kanotföreningen (tens of meters from the shoreline), the SB starts around 08:00 UTC 

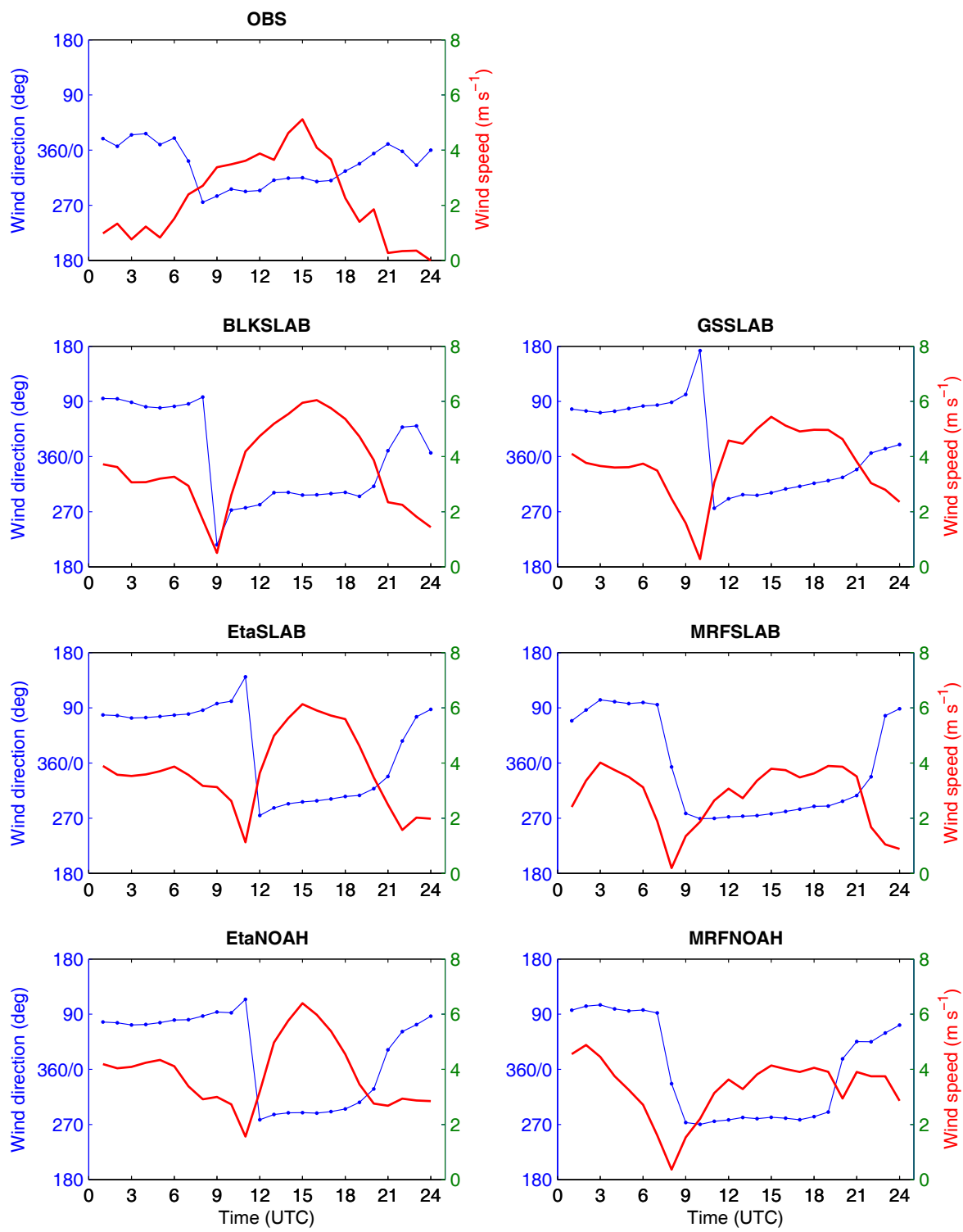

Fig. 2. Observed (OBS) and simulated hourly near-surface wind direction (dotted solid line) and wind speed (solid thick line) with different experiments during the period from 01:00 to 24:00 UTC (8 May 2001) at Kanotföreningen site. Observed near-surface wind is measured at height shown in Table 2. Simulated near-surface wind (10 m a.g.1.) is from the closest grid point to observational site from D4 with 2-km grid spacing. On 8 May 2001, sunrise time in Göteborg (study area) is 03:05 UTC, and sunset time is 19:14 UTC (http://www.timeanddate. com/worldclock/). LT (local time) $=\mathrm{UTC}+2$ over the study area (D4).

[Local Time (LT): UTC $+2 \mathrm{~h}$ ] with a sudden change in wind direction from northwesterly to westerly in the observation (approximately 65 degrees of difference from 07:00 UTC to 08:00 UTC). The wind rotates anti-clockwise ("backing") between 06:00 UTC and 08:00 UTC, and clockwise afterwards through the daytime. Generally, the SB rotates clockwise at most sites, which is typical in the Northern Hemisphere due to the Coriolis force, but the anti-clockwise rotation is possible at some sites because of topographic features (Orlić et al., 1988; Simpson, 1996; Prtenjak and Grisogono, 2007). As seen from Fig. 2, MRFSLAB and MRFNOAH capture the observed backing feature very well, while all other experiments do not capture it. At the Risholmen site near the coastline, there is a veering in wind direction from southeast to southwest between 04:00 and 08:00 UTC in the observation (Fig. 3). The wind begins to blow onshore at around 08:00 UTC (10:00 LT), indicating the onset of SB, marked by a sudden change in wind direction (approximately 80 degrees of difference from 07:00 UTC to 08:00 UTC) and an increase in wind speed. BLKSLAB, GSSLAB, EtaSLAB and EtaNOAH simulate the wind veering reasonably well, while MRFSLAB and MRFNOAH predict the backing of 

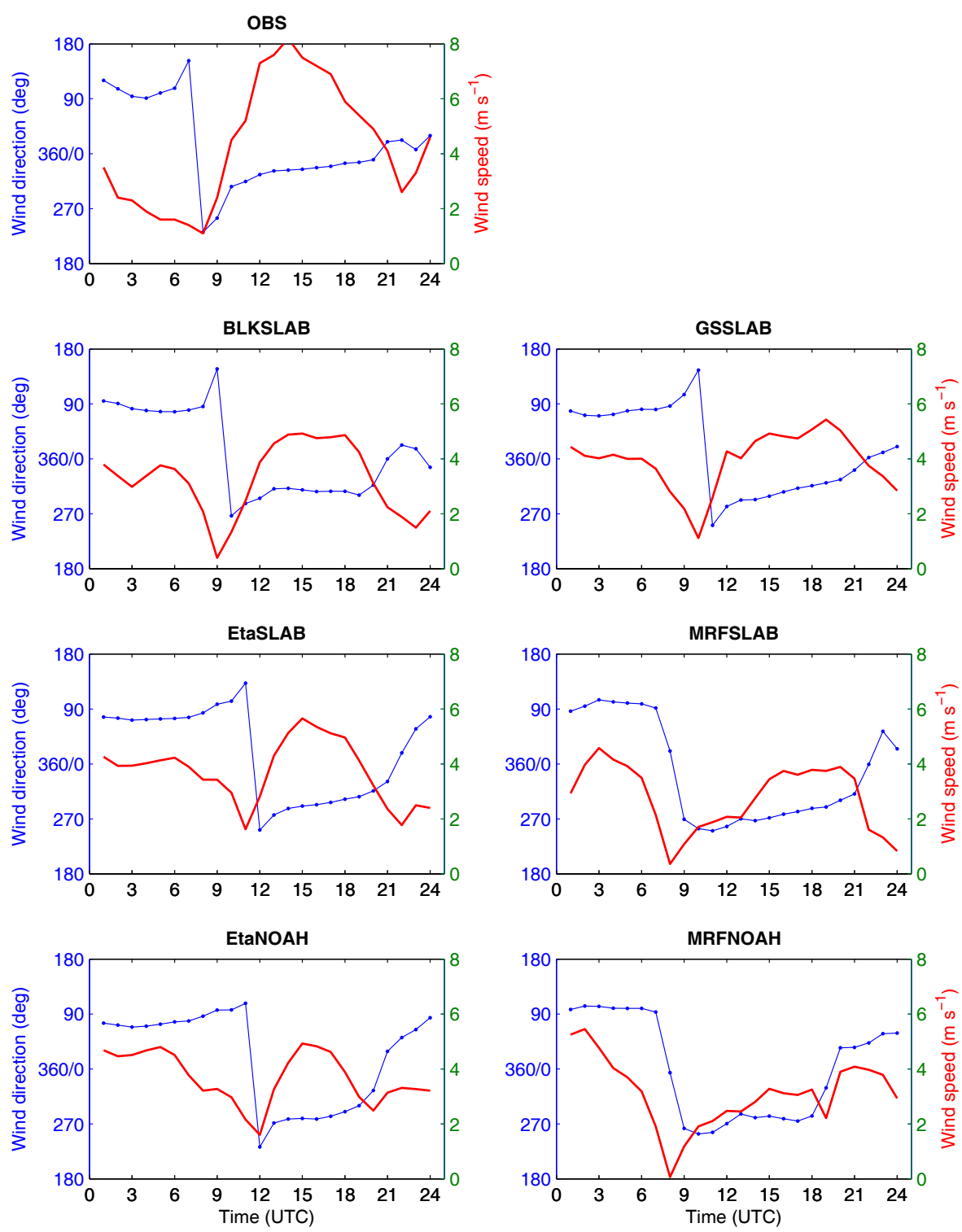

Fig. 3. Same as Fig. 2 but at Risholmen site.

wind direction around 09:00 UTC that is not displayed in the observations. Here it is necessary to point out that the wind at this site was measured at the height of $35 \mathrm{~m}$ a.g.l. (Table 2), and that model results do not show difference in simulated wind direction at this site between the two lowest model levels $(10 \mathrm{~m}$ and $38 \mathrm{~m})$ for any experiment in this study. Also, it could be speculated that differences in the sense of rotation of the wind vector between Kanotföreningen and Risholmen sites, which are not seen in any of the model simulations, are probably due to differences in topography between both sites that are not captured by the model representation of orography.

For the inland sites, the simulated wind seems to be more complex than the observed, as shown in Figs. 4-8 and Ta- bles 3 and 4. At Järnbrott (nearer to the coastline), the simulated SB onset lags 2 to $7 \mathrm{~h}$ compared to the observed, and the simulated SB life span is 1-7 h shorter than the observed. The EtaNOAH shows the poorest performance in predicting the timing and strength at this site, while the BLKSLAB and GSSLAB behave better. At other inland sites (Åby, GVC, Lejonet, Tagene), the simulated wind (or SB) displays large difference in spatial (site) and temporal variations among different experiments. EtaNOAH cannot reproduce the observed SB at all at these four sites, while BLKSLAB and MRFNOAH cannot reproduce the observed SB at Lejonet and Tagene. For the above five inland sites, the GSSLAB performs best in simulating SB onset, life span and strength, and the EtaSLAB and MRFSLAB show similar performance. 

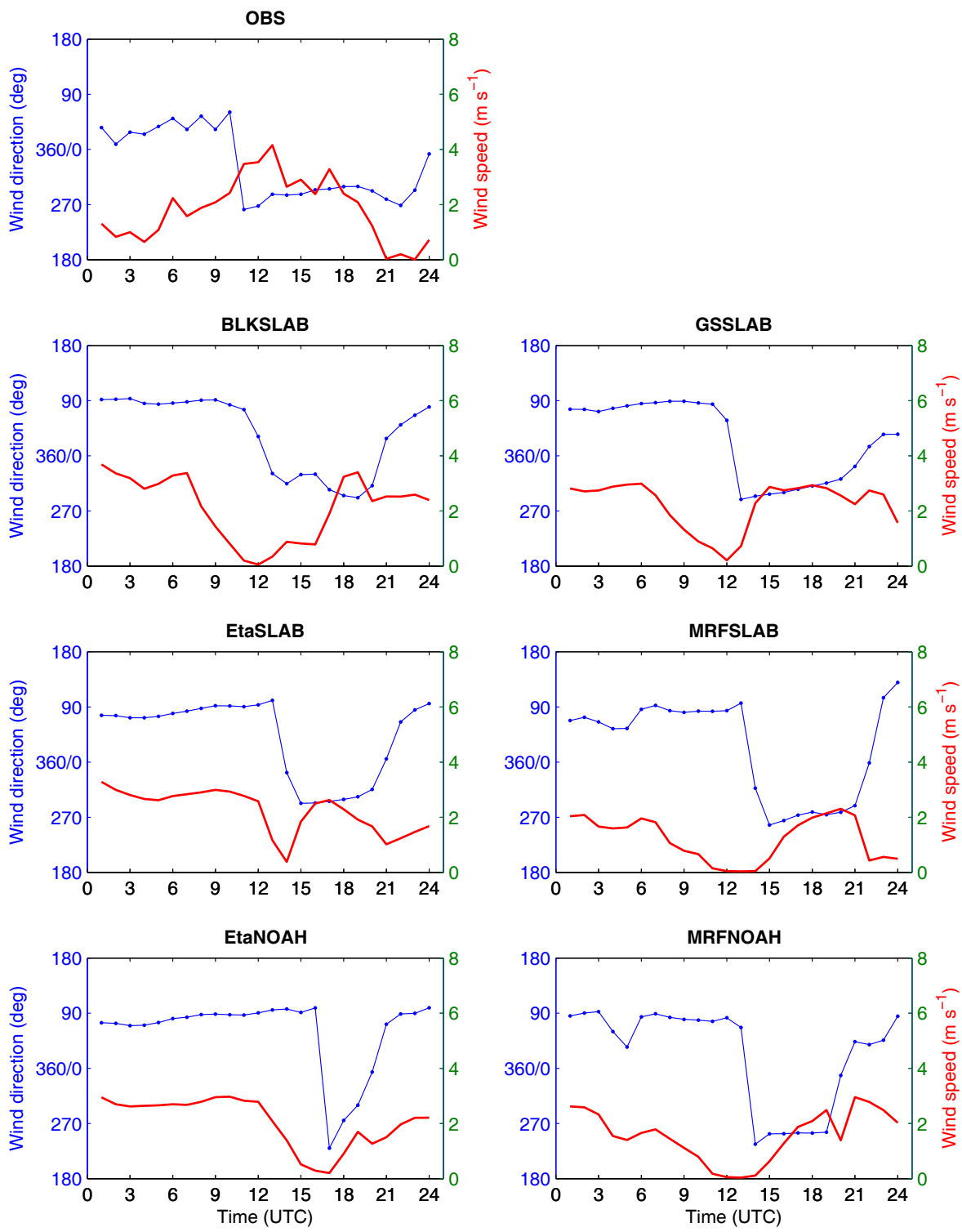

Fig. 4. Same as Fig. 2 but at Järnbrott site.

From the above result analyses, we may speculate that the Blackadar, GS and MRF PBL schemes display better performance in predicting SB timing at the most sites, while the Eta PBL scheme performs most poorly, no matter which LSM scheme it is coupled with (Table 3). This finding for Blackadar, GS, Eta and MRF PBLs from comparisons of BLKSLAB, GSSALB, EtaSLAB and MRFSLAB, which are all coupled to the SLAB LSM, is consistent with that from the study of Srinivas et al. (2007).

Also, as seen from Figs. 2-8 and Table 3, the observed SB displays clear inland penetration, that is, SB onset (from early to late) varies with the distance of sites to the coastline (from near to far). However, the different experiments show highly varying performance in capturing SB inland penetra- tion. The GSSLAB, EtaSLAB and MRFSLAB simulate the SB inland penetration reasonably well, but other combinations of PBL and LSM schemes lack the ability of reproducing SB at further inland sites. Comparisons of EtaSLAB versus EtaNOAH, and MRFSLAB versus MRFNOAH indicate that the complexity of land surface model evidently affects SB simulations. This implies that land surface process parameterization plays an important role in SB modelling.

In addition, it should be mentioned that the model does not simulate any cloud for any experiment in this study. This is in agreement with the observed results (Miao et al., 2008). 

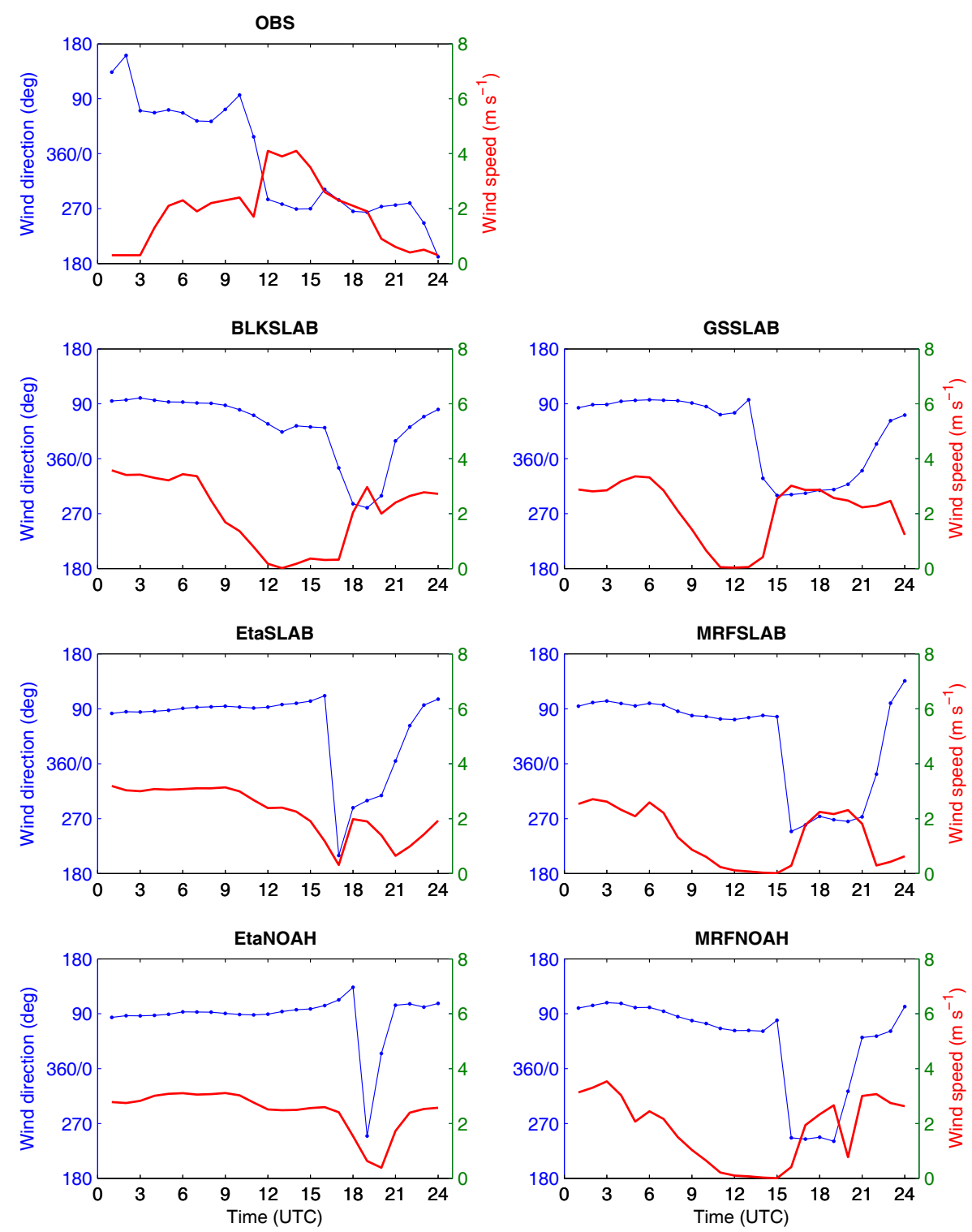

Fig. 5. Same as Fig. 2 but at Åby site.

\section{Sensitivity of simulated sea breeze circulation charac- teristics to PBL and LSM parameterizations}

SB vertical circulation characteristics are usually described by SB depth, inland penetration distance, and maximum horizontal wind speed, as well as maximum vertical velocity ahead of and behind the SB front (e.g., Gronas and Sandvik, 1998; Miao et al., 2003; Srinivas et al., 2007). Also, the distance-height cross-section of $U$ - (or $V$-) and $W$ component along latitude (or longitude) at a certain time is often used to illustrate and characterize SB vertical circulation, depending on the coastline direction. For this reason, we examine the $\mathrm{X}-\mathrm{Z}$ cross section of $U$ - and $W$-component along latitude $57.72^{\circ} \mathrm{N}$ (dashed line in Fig. 1b) at 15:00 UTC 8 May 2001 (Fig. 9), and extract or compute some major characteristic parameters of the circulation, which are summarized in Table 5. These characteristics are used to quantitatively distinguish the difference in simulated SB vertical circulation with different combinations of PBL and LSM parameterization schemes.

Figure 9 shows that different experiments produce significantly different dynamic and thermal structure of sea breeze circulation. The intensity of the circulation cell and the mixed layer depth over the land are different among all experiments. Also, as seen from Table 5, there exists a high diversity among simulated SB inland penetration distance, depth, maximum $U$-component, and updraft and downdraft velocities, as well as $\mathrm{SB}$ circulation intensity (SBCI) index. Among all experiments, GSSLAB predicts the strongest 

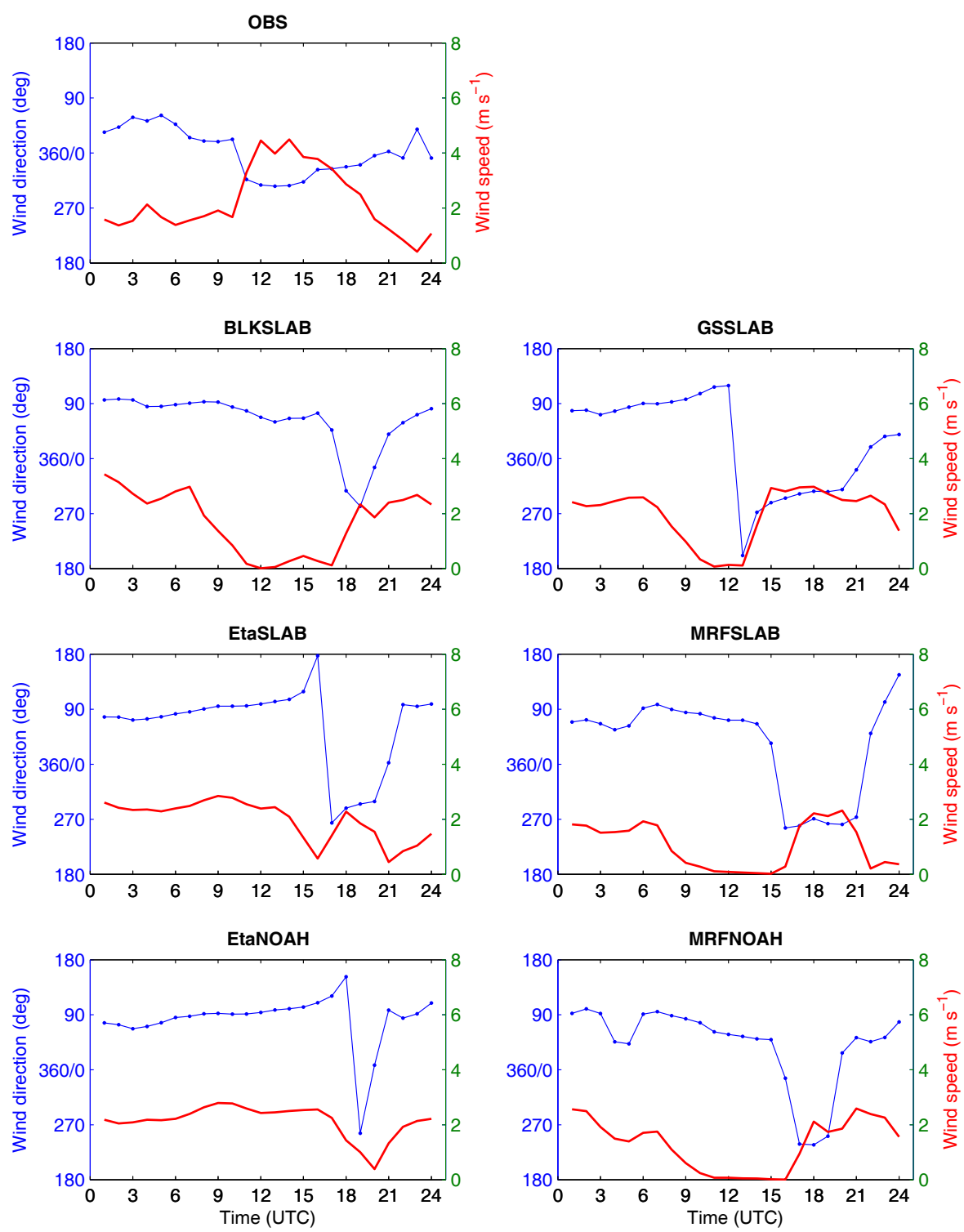

Fig. 6. Same as Fig. 2 but at GVC site.

SB circulation with the largest inland penetration distance $(20 \mathrm{~km}), \mathrm{SB}$ depth $(500 \mathrm{~m}), U$-component $\left(6.7 \mathrm{~m} \mathrm{~s}^{-1}\right)$, updraft and downdraft velocities $\left(67.6 \mathrm{~cm} \mathrm{~s}^{-1}, 20.0 \mathrm{~cm} \mathrm{~s}^{-1}\right)$, and SBCI index $\left(5.87 \mathrm{~m}^{2} \mathrm{~s}^{-2}\right)$. Srinivas et al. (2007) have shown that GSSLAB predicts the most intensive SB front among all experiments (BLKSLAB, GSSLAB, EtaSLAB, and MRFSLAB; See also Table 3) and there is a deep penetration of the SB vertical winds up to $750 \mathrm{hPa}$ level. Our results support their finding. Among all experiments, BLKSLAB, EtaNOAH and MRFNOAH predict shorter inland penetration distance than EtaSLAB and MRFSLAB. This also confirms our findings in Sect. 4 (cf. Table 3) about the model performance in simulating SB inland penetration.
Comparing EtaSLAB with EtaNOAH (Table 5), we find that when coupled with the Eta PBL, the SLAB LSM produces stronger SB circulation than the Noah LSM, which is characterized by larger inland penetration distance, larger updraft and downdraft velocities, as well as larger SBCI. The simulated U-components by these two LSMs are comparable. In contrast, when coupled with the MRF PBL, the SLAB LSM also predicts a larger inland penetration distance than the Noah LSM, and a similar U-component to the Noah LSM, but predicts a smaller updraft velocity maximum and a similar downdraft velocity maximum relative to the Noah LSM. The simulated SBCI index by the SLAB LSM is weaker than that by the Noah LSM. 

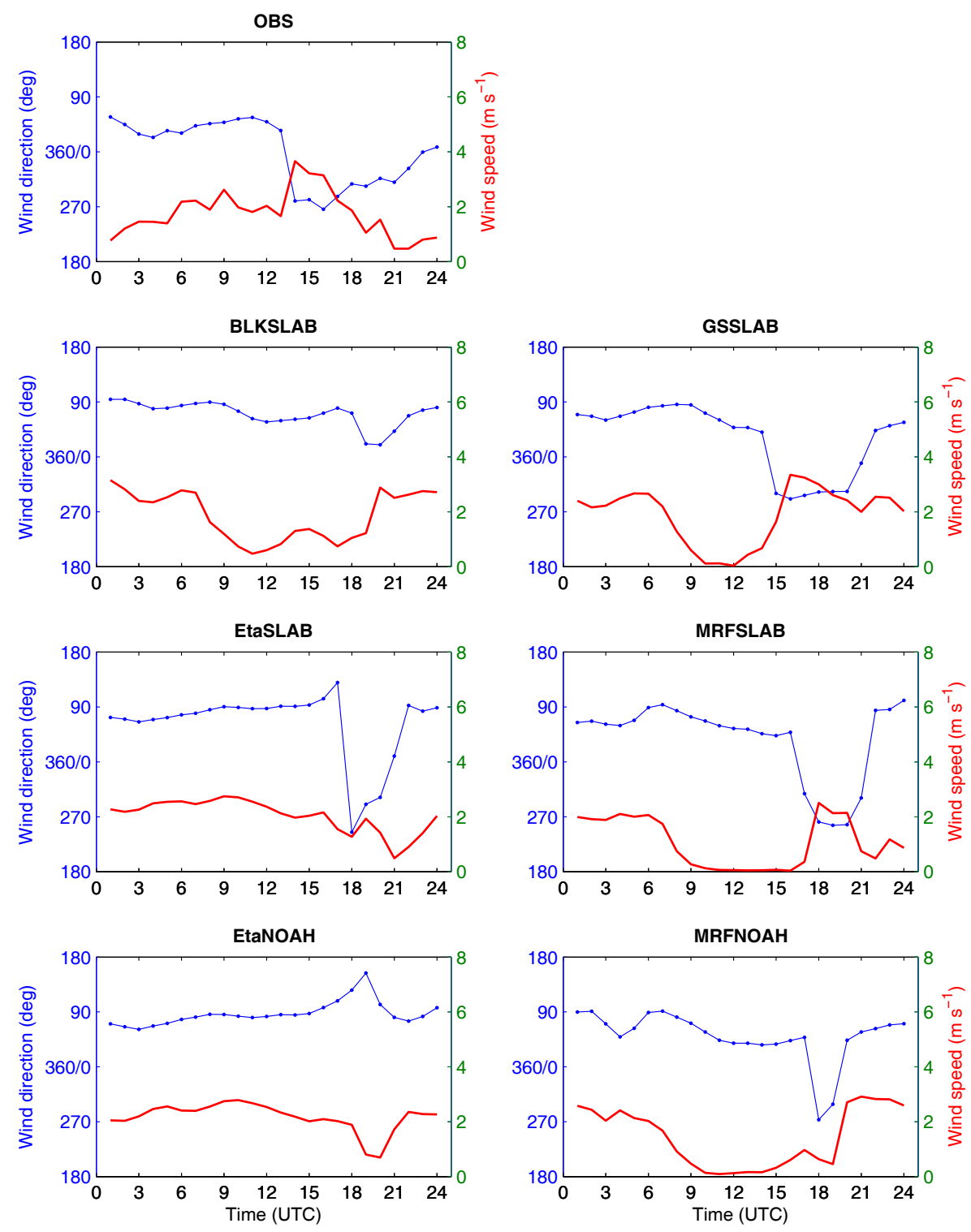

Fig. 7. Same as Fig. 2 but at Lejonet site.

On the other hand, comparing EtaSLAB with MRFSLAB, it is found that when coupled with the SLAB LSM, the Eta PBL produces stronger SB vertical circulation than MRF PBL, which is characterized by larger inland penetration distance, larger U-component maximum, larger updraft velocity maximum, and larger SBCI. The simulated downdraft velocity maxima by these two PBLs are comparable. In contrast, when coupled with Noah LSM, the Eta PBL also predicts a similar inland penetration distance to the MRF PBL, a larger U-component maximum than the MRF PBL, but predicts smaller updraft and downdraft velocity maxima than the MRF PBL. As a result, the simulated SBCI index by the Eta PBL is somewhat weaker than that by the MRF PBL. The BLKSLAB (Blackadar PBL) produces a larger SBCI relative to the MRFSLAB, EtaNOAH and MRFNOAH. Its SBCI index is similar to the EtaSLAB, but much smaller than the GSSALB. It is worthwhile mentioning that our SB simulations are conducted in a coastal urban environment. The previous studies have indicated that urban heat island has impacts on SB development and in particular on the wind fields (Yoshikado, 1992; Ohashi and Kida, 2002; Martilli, 2003; Lo et al., 2007; Freitas et al., 2007; Dandou et al., 2009a). In Fig. 9, the urban areas are located along the distance from 10 to $22 \mathrm{~km}$. As we can see, BLKSLAB and GSSLAB schemes predict a stronger downdraft velocity in front of SB front, forming a secondary vertical circulation, which might be also related to urban heat island circulation caused by urban-rural temperature difference, whereas other 

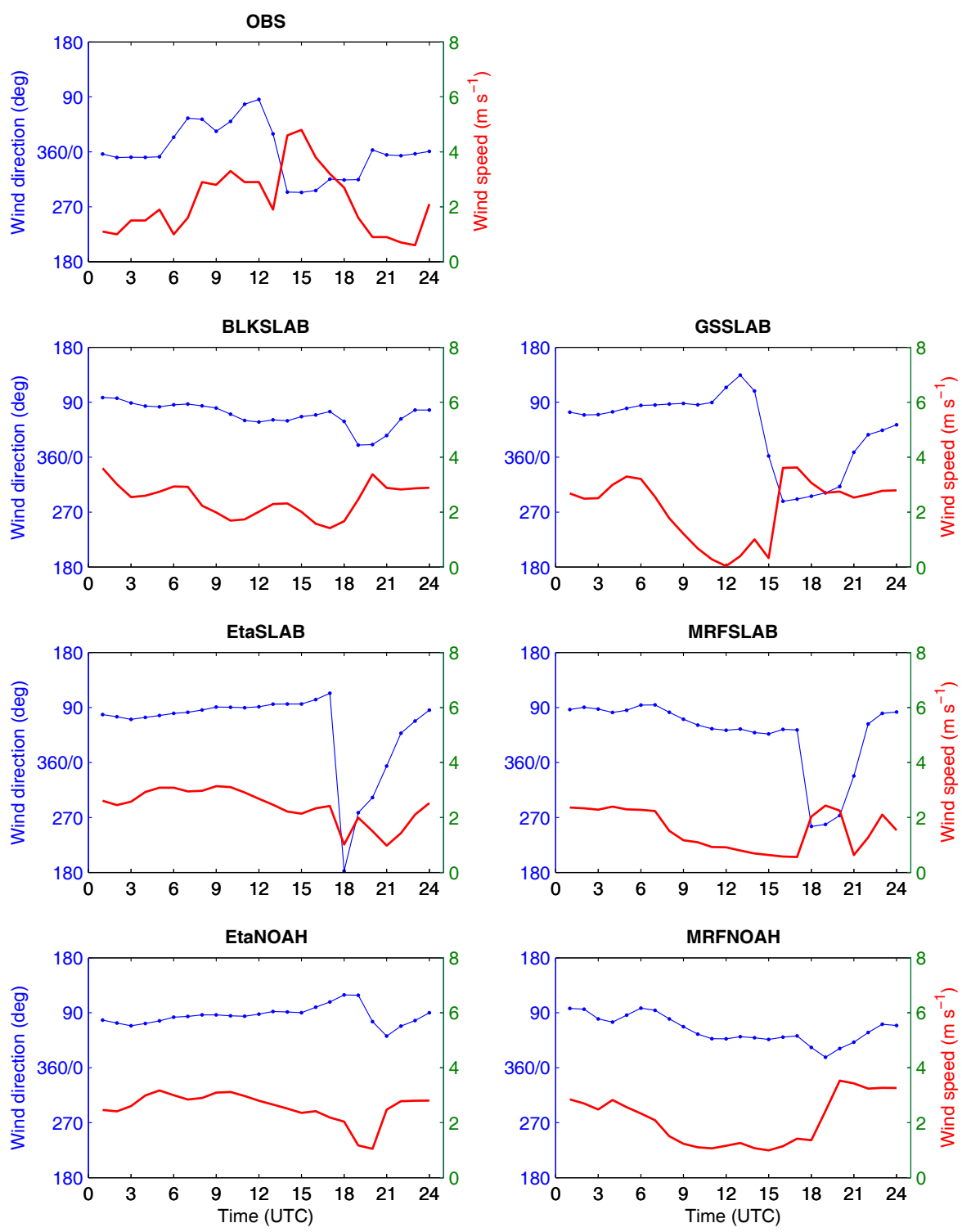

Fig. 8. Same as Fig. 2 but at Tagene site.

schemes do not simulate such circulations very much. This is mainly devoted to impacts of boundary layer and land surface parameterizations implemented in the model.

The above results indicate that the impacts from the combination of PBL and LSM parameterizations on the simulations of SB vertical circulation are significant. The reasons behind these differences resulting from using different combinations of PBL and LSM parameterization schemes need to be further investigated in the future. One of the interesting ways is to apply sea breeze scaling (Steyn, 1998, 2003; Wichink Kruit et al., 2004; Drobinski et al., 2006) to the simulated results, because the recent studies have shown that the sea-breeze speed scale is controlled by surface heat flux whereas the depth scale is controlled by stability (Wichink
Kruit et al., 2004; Porson et al., 2007a, b). Such analyses would assist in highlighting the deficiencies in PBL and/or LSM schemes, and determine the level of coupling between the land surface and the atmosphere.

\section{Summary and conclusions}

In this study, we investigate the impact of different combinations of four PBL schemes with two LSM schemes in the MM5 mesoscale model on simulated sea breeze dynamics with a focus on near-surface wind. Our study differs from most of the previous studies in the literature mainly in that: 1) the combination of Eta and MRF PBLs with the Noah LSM is additionally involved, 2) higher model horizontal and 

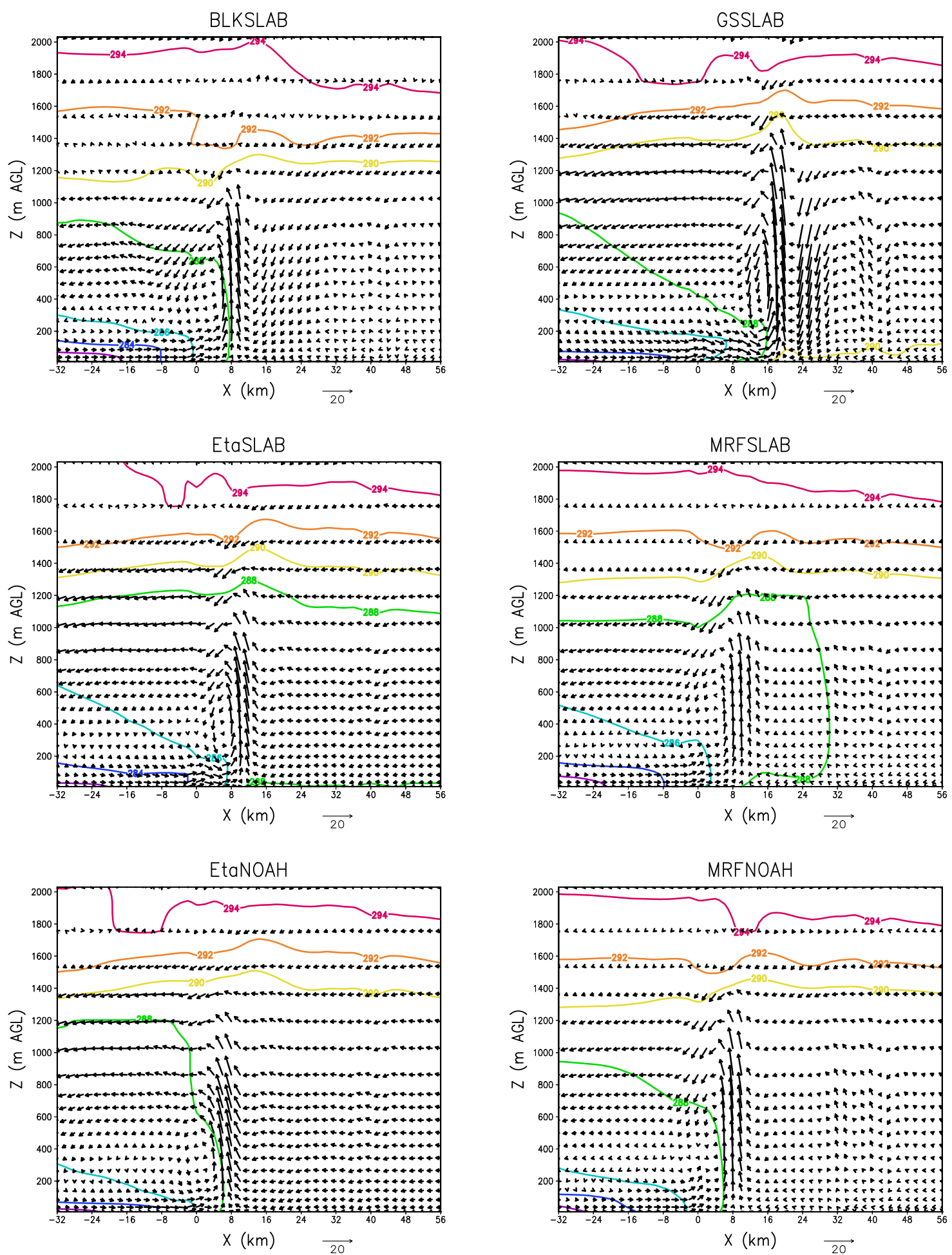

Fig. 9. Vertical cross section of simulated wind vector $\left(U\right.$ - and $W$-component) and potential temperature along $57.72^{\circ} \mathrm{N}(\mathrm{cf}$. Fig. $1 \mathrm{~b})$ with different experiments at 15:00 UTC 8 May 2001. The $W$-component has been multiplied by a factor of 50. Contour interval for potential temperature is $2 \mathrm{~K}$. Number 0 on abscissa (X-axis) indicates coastline. Positive number on $\mathrm{X}$-axis is onshore (inland) distance from the coastline (in kilometers), while negative number is offshore distance from coastline. 
Table 5. Simulated sea breeze (SB) circulation characteristics with different experiments, which are based on vertical cross section of $U$ and $W$ components along $57.72^{\circ} \mathrm{N}$ at 15:00 UTC 8 May 2001 .

\begin{tabular}{|c|c|c|c|c|c|c|c|}
\hline \multirow{2}{*}{\multicolumn{2}{|c|}{ SB circulation characteristics ${ }^{\mathrm{a}}$}} & \multicolumn{6}{|c|}{ Experiment $^{\mathrm{c}}$} \\
\hline & & BS & GS & ES & MS & $\mathrm{EN}$ & $\mathrm{MN}$ \\
\hline \multicolumn{2}{|l|}{ Inland penetration distance $(\mathrm{km})$} & 8 & 20 & 12 & 10 & 8 & 8 \\
\hline \multicolumn{2}{|l|}{ SB depth maximum (m) } & 421 & 500 & 343 & 421 & 343 & 421 \\
\hline \multirow{3}{*}{ U-component maximum } & Magnitude $\left(U_{\mathrm{MAX}}\right)\left(\mathrm{ms}^{-1}\right)$ & 4.9 & 6.7 & 5.6 & 4.5 & 5.7 & 4.5 \\
\hline & At distance from coastline $(\mathrm{km})$ & -2 & 14 & 6 & -2 & -2 & -2 \\
\hline & At height (m a.g.1.) & 38 & 142 & 85 & 38 & 38 & 38 \\
\hline \multirow[t]{3}{*}{ Updraft velocity maximum } & Magnitude $\left(W_{+}\right)\left(\mathrm{cm} \mathrm{s}^{-1}\right)$ & 42.7 & 67.6 & 37.1 & 26.7 & 31.6 & 39.7 \\
\hline & At distance from coastline $(\mathrm{km})$ & 8 & 18 & 10 & 10 & 8 & 8 \\
\hline & At height (m a.g.1.) & 539 & 539 & 539 & 619 & 539 & 699 \\
\hline \multirow[t]{3}{*}{ Downdraft velocity maximum } & Magnitude $\left(W_{-}\right)\left(\mathrm{cm} \mathrm{s}^{-1}\right)$ & -13.3 & -20.0 & -12.5 & -14.3 & -6.3 & -14.6 \\
\hline & At distance from coastline $(\mathrm{km})$ & 6 & 16 & 8 & 4 & 0 & 2 \\
\hline & At height (m a.g.1.) & 1109 & 1647 & 1450 & 1109 & 1278 & 1109 \\
\hline \multicolumn{2}{|c|}{ SB circulation intensity ${ }^{b}\left(\mathrm{~m}^{2} \mathrm{~s}^{-2}\right)$} & 2.744 & 5.869 & 2.778 & 1.854 & 2.160 & 2.444 \\
\hline
\end{tabular}

a Inland penetration distance is defined as the distance at which the magnitude of $U$-component at the lowest model level (10 m a.g.1.) becomes less than $0.0 \mathrm{~m} \mathrm{~s}^{-1}$ from positive to negative; SB depth maximum is defined as the maximum depth of a consistently positive U-component near the coastline; $U_{\mathrm{MAX}}$ is defined as the maximum positive U-component indicating $\mathrm{SB}$ (onshore); $W_{+}$is defined as the maximum $W$-component (positive) ahead of the SB front, and $W_{-}$is defined as the minimum $W$-component (negative) behind the SB front (cf. Miao et al., 2003).

${ }^{\mathrm{b}} \mathrm{SB}$ circulation intensity $(\mathrm{SBCI})$ is defined as: $\mathrm{SBCI}=U_{\mathrm{MAX}} \times\left(W_{+}-W_{-}\right)$.

c Refer to Table 1 for abbreviations of experiments.

vertical resolutions are used, and 3) the timing and strength of SB circulation is evaluated and intercompared.

The experiments aim at the simulations of a typical SB case (8 May 2001) over the Swedish west coast. The simulated $10-\mathrm{m}$ winds are compared among different combinations of PBL and LSM schemes, and compared against the observed near-surface wind from the GÖTE2001 field campaign. The focus is on SB timing and wind direction. The main conclusions are:

- All combinations of PBL and LSM schemes can reproduce the observed SB at the coastal sites (Kanotföreningen, Risholmen) and the near-coastal site (Järnbrott) to a larger extent, but some differences in the simulated SB onset, life span and strength do exist. All experiments predict a delayed SB. BLKSLAB, MRFS$\mathrm{LAB}$ and MRFNOAH show better performance in predicting SB onset and life span at the two coastal sites. BLKSLAB and GSSLAB perform better at the Järnbrott site, and EtaSLAB, MRFSLAB and MRFNOAH exhibit similar performance at this site. As a whole, BLKSLAB is shown to perform the best among the six examined combinations of the PBL and LSM schemes in reproducing the $\mathrm{SB}$ onset and life span at the coastal or near-coastal sites.

- GSSLAB, EtaSLAB and MRFSLAB predict SB inland penetration reasonably well compared to the observed
SB, while BLKSLAB, EtaNOAH and MRFNOAH predict shorter inland distance penetration distance.

- The simulated SB characteristics, especially the intensity of the SB vertical circulation, are highly variable. GSSLAB predicts the strongest SB circulation, and BLKSLAB predicts a similar intensity of SB circulation to EtaSLAB and MRFNOAH. MRFSLAB and EtaSLAB predict somewhat weaker SB circulation. There is an evident difference between SLAB and Noah LSMs in simulated SB circulation intensity (SBCI) (EtaSLAB versus EtaNOAH, and MRFSLAB versus MRFNOAH).

In summary, choosing different combinations of PBL and LSM parameterization schemes in MM5 as applied to SB simulations exhibits different model performance in simulated SB timing, inland penetration distance, and circulation intensity. These differences are not only due to combination (coupling) of the different PBL schemes with the same LSM scheme (e.g., BLKSLAB, GSSLAB, EtaSLAB and MRFSLAB for SLAB LSM; EtaNOAH and MRFNOAH for Noah LSM), but also due to combination of different LSM schemes with the same PBL scheme (e.g., EtaSLAB and EtaNOAH for Eta PBL; MRFSLAB and MRFNOAH for MRF PBL).

Therefore, choosing an appropriate combination of PBL and LSM schemes is important for MM5 applications to SB simulations, especially when applied to air quality modelling over coastal urban areas. Moreover, using the advanced Noah 
LSM scheme does not imply better results than with the simpler SLAB LSM scheme.

At last, it is necessary to point out that: 1) more case studies of SB under different large-scale forcing conditions and/or over different geographical regions (e.g., complex terrain) should be done to generalize our findings, and 2) application of sea breeze scaling to the simulated results could significantly improve our understanding of the differences caused by using different combination of PBL and LSM parameterization schemes in the SB simulations.

Acknowledgements. The study was funded by Adlerbertska Research Foundation (Adlerbertska Forskingsstiftelsen, Sweden) through the project Sea Breeze Study over the Swedish west coast by using Mesoscale Meteorological Model: Soil-VegetationAtmosphere Interaction to Junfeng Miao. Additional financial support to Junfeng Miao for this research is provided by the Canadian Foundation for Climate and Atmospheric Sciences (CFCAS) through a sub-project on Sea Breeze and Fog Modelling within Interdisciplinary Marine Environmental Prediction in the Atlantic Coastal Region ("The Lunenburg Bay Project"). The authors are greatly thankful to Katarina Borne (University College of Borås, Sweden) and Jesper Lindgren (Environment Administration of the City of Gothenburg, Sweden) for the GÖTE2001 data support. Deliang Chen's contribution is Contribution Number 26 from TELLUS, the Centre for Earth Systems Science at University of Gothenburg. Moreover, this study is also supported by the Scientific Research Fund of Nanjing University of Information Science and Technology (NUIST) and the Dean's Fund of College of Atmospheric Sciences of NUIST.

Topical Editor F. D'Andrea thanks two anonymous referees for their help in evaluating this paper.

\section{References}

Abbs, D. and Physick, W.: Sea-breeze observations and modeling: A review, Aust. Meteor. Mag., 41, 7-19, 1992.

Akylas, E., Kotroni. V., and Lagouvardos, K.: Sensitivity of highresolution operational weather forecasts to the choice of the planetary boundary layer scheme, Atmos. Res., 84, 49-57, 2007.

Angevine, W. M., Tjernström, M., and Žagar, M.: Modeling of the coastal boundary layer and pollutant transport in New England, J. Appl. Meteor. Climatol., 45, 137-154, 2006.

Augustin, P., Delbarre, H., Lohou, F., Campistron, B., Puygrenier, V., Cachier, H., and Lombardo, T.: Investigation of local meteorological events and their relationship with ozone and aerosols during an ESCOMPTE photochemical episode, Ann. Geophys., 24, 2809-2822, 2006, http://www.ann-geophys.net/24/2809/2006/.

Berg, L. K. and Zhong, S. Y.: Sensitivity of MM5-simulated boundary layer characteristics to turbulence parameterizations, J. Appl. Meteorol., 44, 1467-1483, 2005.

Bélair, S. and Mailhot, J.: Impact of horizontal resolution on the numerical simulation of a midlatitude squall line: Implicit versus explicit condensation, Mon. Weather Rev., 129, 2362-2376, 2001.

Bianco, L., Tomassetti, B., Coppola, E., Fracassi, A., Verdecchia, M., and Visconti, G.: Thermally driven circulation in a region of complex topography: comparison of wind-profiling radar measurements and MM5 numerical predictions, Ann. Geophys., 24, 1537-1549, 2006, http://www.ann-geophys.net/24/1537/2006/.

Blackadar, A. K.: Modeling the nocturnal boundary layer. Preprints, Third Symposium on Atmospheric Turbulence, Diffusion and Air Quality, Raleigh, NC, American Meteorological Society, 4649, 1976.

Blackadar, A. K.: High resolution models of the planetary boundary layer, in: Advances in Environmental Science and Engineering, edited by: Pfafflin, J. and Ziegler, E., vol. 1, no. 1, Gordon and Breach Publishers, Newark, 50-85, 1979.

Borne, K., Chen, D., and Nunez, M.: A method for finding sea breeze days under stable synoptic conditions and its application to the Swedish west coast, Int. J. Climatol., 18, 901-914, 1998.

Borne, K., Chen, D., Miao, J.-F., Achberger, C., Lindgren, J., Hallquist, M., Pettersson, J., Haeger Eugensson, M., Wyser, K., Eliasson, I., and Langner, J.: Data report on measurements of meteorological- and air pollution variables during the campaign GÖTE-2001, Research Report C67, Earth Sciences Centre, Göteborg University, Göteborg, Sweden, 28 pp., 2005.

Bossioli, E., Tombrou, M., Dandou, A., Athanasopoulou, E., and Varotsos, K. V.: The role of planetary boundary-layer parameterizations in the air quality of an urban area with complex topography, Bound.-Lay. Meteorol., 131, 53-72, 2009.

Braun, S. A. and Tao, W. K.: Sensitivity of high-resolution simulations of Hurricane Bob (1991) to planetary boundary layer parameterizations, Mon. Weather Rev., 128, 3941-3961, 2000.

Bright, D. R. and Mullen, S. L.: The sensitivity of the numerical simulation of the southwest monsoon boundary layer to the choice of PBL turbulence parameterization in MM5, Wea. Forecast., 17, 99-114, 2002.

Chen, F. and Dudhia, J.: Coupling an advanced land surfacehydrology model with the Penn State-NCAR MM5 modeling system. Part I: Model implementation and sensitivity, Mon. Weather Rev., 129, 569-585, 2001a.

Chen, F. and Dudhia, J.: Coupling an advanced land surfacehydrology model with the Penn State-NCAR MM5 modeling system. Part II: Preliminary model validation, Mon. Weather Rev., 129, 587-604, 2001b.

Colby Jr., F. P.: Simulation of the New England sea breeze: The effect of grid spacing, Wea. Forecast., 19, 277-285, 2004.

Dandou, A., Tombrou, M., and Soulakellis, N.: The influence of the City of Athens on the evolution of the sea-breeze front, Bound.Lay. Meteorol., 131, 35-51, 2009a.

Dandou, A., Tombrou, M., Schäfer, K., Emeis, S., Protonotariou, A. P., Bossioli, E., Soulakellis, N., and Suppan, P.: A Comparison between modelled and measured mixing-layer height over Munich, Bound.-Lay. Meteorol., 131, 425-440, $2009 \mathrm{~b}$.

Ding, A. J., Wang, T., Zhao, M., Wang, T. J., and Li, Z. K.: Simulation of sea-land breezes and a discussion of their implications on the transport of air pollution during a multi-day ozone episode in the Pearl River Delta of China, Atmos. Environ., 38, 6737-6750, 2004.

Drobinski, P., Bastin, S., Dabas, A., Delville, P., and Reitebuch, O.: Variability of three-dimensional sea breeze structure in southern France: observations and evaluation of empirical scaling laws, Ann. Geophys., 24, 1783-1799, 2006, http://www.ann-geophys.net/24/1783/2006/. 
Dudhia, J.: Numerical study of convection observed during the Winter Monsoon Experiment using a mesoscale two-dimensional model, J. Atmos. Sci., 46, 3077-3107, 1989.

Dudhia, J.: A multi-layer soil temperature model for MM5, Reprints, Sixth Annual PSU/NCAR Mesoscale Model Users' Workshop, Boulder, CO, NCAR, 49-50, 1996.

Freitas, E. D., Rozoff, C. M., Cotton, W. R., and Silva Dias, P. L.: Interactions of an urban heat island and sea-breeze circulations during winter over the metropolitan area of São Paulo, Brazil, Bound.-Lay. Meteorol., 122, 43-65, 2007.

Furberg, M., Steyn, D. G., and Baldi, M.: The climatology of sea breezes on Sardinia, Int. J. Climatol., 22, 917-932, 2002.

Grell, G. A., Dudhia, J., and Stauffer, D. R.: A description of the fifth-generation Penne State/NCAR Mesoscale Model (MM5), NCAR Technical Note, NCAR/TN-398+STR, National Center for Atmospheric Research, Boulder, CO, 122 pp., 1995.

Gronas, S. and Sandvik, A. D.: Numerical simulations of sea and land breezes at high latitudes, Tellus, 50A, 468-489, 1998.

Gustavsson, T., Lindqvist, S., Borne, K., and Bogren, J.: A study of sea and land breezes in an Archipelago on the west coast of Sweden, Int. J. Climatol., 15, 785-800, 1995.

Han, Z., Ueda, H., and An, J.: Evaluation and intercomparison of meteorological predictions by five MM5-PBL parameterizations in combination with three land-surface models, Atmos. Environ., 42, 233-249, 2008.

Hong, S. Y. and Pan, H. L.: Nonlocal boundary layer vertical diffusion in a medium-range forecast model, Mon. Weather Rev., 124, 2322-2339, 1996.

Janjić, Z. I.: The step-mountain coordinate: Physical package, Mon. Weather Rev., 118, 1429-1443, 1990.

Janjić, Z. I.: The step-mountain Eta coordinate model: Further developments of the convection, viscous sublayer, and turbulence closure schemes, Mon. Weather Rev., 122, 927-945, 1994.

Kain, J. S.: The Kain-Fritsch convective parameterization: An update, J. Appl. Meteorol., 43, 170-181, 2004.

Lo, J. C. F., Lau, A. K. H., Chen, F., Fung, J. C. H., and Leung, K. K. M.: Urban modification in a mesoscale model and the effects on the local circulation in the Pearl River Delta Region, J. Appl. Meteor. Climatol., 46, 457-476, 2007.

Malda, D., Vilà-Guerau de Arellano, J., van den Berg, W. D., and Zuurendonk, I. W.: The role of atmospheric boundary layersurface interactions on the development of coastal fronts, Ann. Geophys., 25, 341-360, 2007,

http://www.ann-geophys.net/25/341/2007/.

Manabe, S.: Climate and the ocean circulation - I. The atmospheric circulation and the hydrology of the Earth's surface, Mon. Weather Rev., 97, 739-774, 1969.

Mao, Q., Gautney, L. L., Cook, T. M., Jacobs, M. E., Smith, S. N., and Kelsoe, J. J.: Numerical experiments on MM5-CMAQ sensitivity to various PBL schemes, Atmos. Environ., 40, 30923110, 2006.

Martilli, A.: A two-dimensional numerical study of the impact of a city on atmospheric circulation and pollutant dispersion in a coastal environment, Bound.-Lay. Meteorol., 108, 91-119, 2003.

Miao, J.-F.: Meteorological modelling in coastal areas - Local climate and air quality, Ph.D. thesis, A107, Earth Sciences Centre, Göteborg University, Göteborg, Sweden, 190 pp., 2006.

Miao, J.-F., Kroon, L. J. M., Vilà-Guerau de Arellano, J., and Holtslag, A. A. M.: Impacts of topography and land degradation on the sea breeze over eastern Spain, Meteorol. Atmos. Phys., 84, 157-170, 2003.

Miao, J.-F., Chen, D., and Wyser, K.: Modelling subgrid scale dry deposition velocity of $\mathrm{O}_{3}$ over the Swedish west coast with MM5-PX model, Atmos. Environ., 40, 415-429, 2006.

Miao, J.-F., Chen, D., and Borne, K.: Evaluation and comparison of Noah and Pleim-Xiu land surface models in MM5 using GÖTE2001 data: Spatial and temporal variations in nearsurface air temperature, J. Appl. Meteor. Climatol., 46, 15871605, 2007.

Miao, J.-F., Chen, D., Wyser, K., Borne, K., Lindgren, J., Svensson, M. K., Thorsson, S., Achberger, C., and Almkvist, E.: Evaluation of MM5 mesoscale model at local scale for air quality applications over the Swedish west coast: Influence of PBL and LSM parameterizations, Meteorol. Atmos. Phys., 99, 77-103, 2008.

Miller, S. T. K., Keim, B. D., Talbot, R. W., and Mao, H.: Sea breeze: Structure, forecasting, and impacts, Rev. Geophys., 41(3), 1011, doi:10.1029/2003RG000124, 2003.

Mlawer, E. J., Taubman, S. J., Brown, P. D., Iacono, M. J., and Clough, S. A.: Radiative transfer for inhomogeneous atmospheres: RRTM, a validated correlated-K model for the longwave, J. Geophys. Res., 102(D14), 16663-16682, 1997.

Oh, I. B., Kim, Y. K., Lee, H. W., and Kim, C. H.: An observational and numerical study of the effects of the late sea breeze on ozone distributions in the Busan metropolitan area, Korea, Atmos. Environ., 40, 1284-1298, 2006.

Ohashi, Y. and Kida, H.: Local circulations developed in the vicinity of both coastal and inland urban areas: A numerical study with a mesoscale atmospheric model, J. Appl. Meteorol., 41, 30 45, 2002.

Orlić, M., Penzar, B., and Penzar, I.: Adriatic sea and land breezes: Clockwise versus anticlockwise rotation, J. Appl. Meteorol., 27, 675-679, 1988.

Pérez, C., Jiménez, P., Jorba, O., Sicard, M., and Baldasano, J. M.: Influence of the PBL scheme on high-resolution photochemical simulations in an urban coastal area over the Western Mediterranean, Atmos. Environ., 40, 5274-5297, 2006.

Pleim, J. E.: A combined local and nonlocal closure model for the atmospheric boundary layer. Part II: application and evaluation in a mesoscale meteorological model, J. Appl. Meteorol., 46, 13961409, 2007.

Porson, A., Steyn, D. G., and Schayes, G.: Sea-breeze scaling from numerical model simulations, Part I: Pure sea breezes, Bound.Lay. Meteorol., 122, 17-29, 2007a.

Porson, A., Steyn, D. G., and Schayes, G.: Sea-breeze scaling from numerical model simulations, part II: Interaction between the sea breeze and slope flows, Bound.-Lay. Meteorol., 122, 31-41, 2007b.

Prezerakos, N. G.: Characteristics of the sea breeze in Attica, Greece, Bound.-Lay. Meteorol., 36, 245-266, 1986.

Prtenjak, M. T. and Grisogono, B.: Idealised numerical simulations of diurnal sea breeze characteristics over a step change in roughness, Meteorol. Z., 11, 345-360, 2002.

Prtenjak, M. T. and Grisogono, B.: Sea/land breeze climatological characteristics along the northern Croatian Adriatic coast, Theor. Appl. Climatol., 90, 201-215, 2007.

Seaman, N. L.: Meteorological modeling for air-quality assessments, Atmos. Environ., 34, 2231-2259, 2000.

Shafran, P. C., Seaman, N. L., and Gayno, G. A.: Evaluation of nu- 
merical predictions of boundary layer structure during the Lake Michigan ozone study, J. Appl. Meteorol., 39, 412-426, 2000.

Simpson, J. E.: Sea breeze and local winds. Cambridge University Press, UK, 234 pp., 1994.

Simpson, J. E.: Diurnal changes in sea-breeze direction, J. Appl. Meteorol., 35, 1166-1169, 1996.

Srinivas, C. V., Venkatesan, R., and Bagavath Singh, A.: Sensitivity of mesoscale simulations of land-sea breeze to boundary layer turbulence parameterization, Atmos. Environ., 41, 2534-2548, 2007.

Steyn, D. G.: Scaling the vertical structure of sea breezes, Bound.Lay. Meteorol., 86, 505-524, 1998.

Steyn, D. G.: Scaling the vertical structure of sea breezes revised. Bound.-Lay. Meteorol., 107, 177-188, 2003.

Thomsen, G. L. and Smith, R. K.: The importance of the boundary layer parameterization in the prediction of low-level convergence lines, Mon. Weather Rev., 136, 2173-2185, 2008.

Tombrou, M., Dandou, A., Helmis, C., Akylas, E., Angelopoulos, G., Flocas, H., Assimakopoulos, V., and Soulakellis, N.: Model evaluation of the atmospheric boundary layer and mixed-layer evolution, Bound.-Lay. Meteorol., 124, 61-79, 2007.

Wichink Kruit, R. J., Holtslag, A. A. M., and Tijm, A. B. C.: Scaling of the sea-breeze strength with observations in the Netherlands, Bound.-Lay. Meteorol., 112, 369-380, 2004.

Wisse, J. S. P. and Vilà-Guerau de Arellano, J.: Analysis of the role of the planetary boundary layer schemes during a severe convective storm, Ann. Geophys., 22, 1861-1874, 2004, http://www.ann-geophys.net/22/1861/2004/.
Yoshikado, H.: Numerical study of the daytime urban effect and its interaction with the sea breeze, J. Appl. Meteorol., 31, 11461164, 1992.

Zängl, G., Gohm, A., and Obleitner, F.: The impact of the PBL scheme and the vertical distribution of model layers on simulations of Alpine foehn, Meteorol. Atmos. Phys., 99, 105-128, 2008.

Zhang, D. L. and Anthes, R. A.: A high-resolution model of the planetary boundary layer - Sensitivity tests and comparisons with SESAME-79 data, J. Appl. Meteorol., 21, 1594-1609, 1982.

Zhang, D. L. and Zheng, W. Z.: Diurnal cycles of surface winds and temperatures as simulated by five boundary layer parameterizations, J. Appl. Meteorol., 43, 157-169, 2004.

Zhong, S. Y. and Takle, E. S.: The effects of large-scale winds on the sea-land-breeze circulations in an area of complex coastal heating, J. Appl. Meteorol., 32, 1181-1195, 1993.

Zhong, S. Y., In, H. J., Bian, X. D., Charney, J., Heilman, W., and Potter, B.: Evaluation of real-time high-resolution MM5 predictions over the Great Lakes region, Wea. Forecast., 20, 63-81, 2005.

Zhong, S. Y., In, H. J., and Clements, C.: Impact of turbulence, land surface, and radiation parameterizations on simulated boundary layer properties in a coastal environment, J. Geophys. Res., 112, D13110, doi:10.1029/2006JD008274, 2007.

Zhu, M. and Atkinson, B. W.: Observed and modelled climatology of the land-sea breeze circulation over the Persian Gulf, Int. J. Climatol., 24, 883-905, 2004. 